\title{
Loss of heterozygosity and loss of expression of the DCC gene in gastric cancer
}

\author{
Dian-Chun Fang, Jeremy R Jass, Dong-Xu Wang
}

\begin{abstract}
Aim-To investigate the role of DCC gene inactivation in the development and progression of gastric cancer.

Methods-Loss of heterozygosity and loss of expression of the DCC gene was studied in 51 surgical specimens of gastric cancer using detection based on polymerase chain reaction.

Results-Loss of heterozygosity was found in $35.3 \%$ (18 of 51 ) of specimens and was detected more often in stage III and IV $(50 \%)$ than in stage I and II cancers $(14.3 \%)$ $(p<0.05)$. Occurrence of loss of heterozygosity was not correlated with histological type, tumour size, depth of invasion, or lymph node metastasis. Loss of expression was found in $49 \%$ of cases ( 25 of 51 ). Loss of expression was not significantly correlated with any clinicopathological variable. Conclusions-Loss of heterozygosity and loss of expression of the DCC gene are often encountered in gastric cancer. Loss of heterozygosity of the DCC gene is a late event and associated with malignant progression.

(F Clin Pathol 1998;51:593-596)
\end{abstract}

Keywords: gastric cancer; DCC gene; heterozygosity; mRNA expression

Tumour suppressor genes play an important role in regulating normal cellular proliferation. ${ }^{12}$ Conversely, inactivation of tumour suppressor genes at both alleles may allow a cell to escape normal growth control and so acquire a malignant phenotype. This inactivation may occur by a variety of mechanisms including deletion, rearrangement, point mutation, and binding of suppressor gene products with viral or cellular inactivating proteins. ${ }^{13}$ The Deleted in Colorectal Cancer (DCC) gene was cloned following the demonstration of frequent deletions affecting the $18 \mathrm{q} 21$ region in colon cancer. ${ }^{4}$ Subsequently, loss of heterozygosity or loss of expression of DCC has been reported in several additional tumour types including malignancies of the breast, ${ }^{67}$ pancreas, ${ }^{8}$ prostate,${ }^{9}$ and testis, ${ }^{10}$ glioblastoma, ${ }^{11}{ }^{12}$ neuroblastoma, ${ }^{13}$ and haematological malignancies. ${ }^{14}{ }^{15}$ In a previous study of human gastric cancer, loss of heterozygosity of $18 \mathrm{q}$ was detected in more than $60 \%$ of cases. ${ }^{16}$ However, little is known of the role of loss of expression of the DCC gene in gastric cancer. To investigate the effects of alteration of the DCC gene on the development and progression of gastric cancer, we studied loss of heterozygosity and loss of expression of this gene using detection methods based on polymerase chain reaction.

\section{Methods}

TISSUE SPECIMENS

Tumour and corresponding non-cancerous tissues were obtained from 51 patients who underwent surgical resection for gastric carcinoma between January 1995 and October 1997 at the Southwest Hospital, Chongqing. No radiotherapy or chemotherapy preceded tumour excision. Each pair of tumour and corresponding non-tumour tissue was taken immediately after the resection and stored at $-80^{\circ} \mathrm{C}$ for later use. A $6 \mu \mathrm{m}$ section was cut from each specimen and stained with haematoxylin and eosin for pathological diagnosis. After diagnostic confirmation, a visual assessment was made of the approximate proportion of tumour cells versus normal cells in tumour samples. Only those specimens in which tumour cells represented $50 \%$ of the tumour tissue were accepted for loss of heterozygosity and loss of expression analysis.

TOTAL RNA ISOLATION AND DNA EXTRACTION Total RNA was prepared from tumour and non-cancerous tissue using the acid guanidinium thiocyanate method $^{17}$ and high molecular weight DNA was extracted by proteinase $\mathrm{K}$ digestion and phenol-chloroform-isoamylalcohol extraction as previously described. ${ }^{18}$

\section{RT-PCR ASSAY OF DCC GENE EXPRESSION}

Reverse transcriptase polymerase chain reaction (RT-PCR) was performed as described previously with some modifications. ${ }^{19}$ DCC complementary DNA was amplified at $94^{\circ} \mathrm{C}$ for 40 seconds, $49^{\circ} \mathrm{C}$ for 40 seconds, and $72^{\circ} \mathrm{C}$ for one minute for 35 cycles. DCC primers are located on exons 0 and $\mathrm{P}$ and amplify a 233 base pair fragment from human mRNA. ${ }^{20} \mathrm{~A}$ fragment of this size cannot be amplified from genomic DNA, since the primers were designed to frame sequences that cross an intron on the DCC gene. RT-PCR without RNA or without reverse transcriptase was included in each experiment as negative controls; primers used were 5'-TTCCGCCATGGTTTTTAAATCA-3' (DCC sense), which corresponds to nucleotides 986-1007 in the cDNA sequence, and 5'-AGCCTCATTTTCAGCCACACA-3' (DCC antisense), which corresponds to nucleotides 1218-1198. Amplifiable cDNA was demonstrated in lanes showing DCC loss of expression using $\beta_{2}$ microglobulin primers.

PCR LOSS OF HETEROZYGOSITY ANALYSIS Genomic DNA (50 to $500 \mathrm{ng}$ ) was held at $95^{\circ} \mathrm{C}$ for five minutes in $20 \mu \mathrm{l}$ buffer containing $10 \mathrm{mM}$ Tris ( $\mathrm{pH} \mathrm{8.3),} 5 \mathrm{mM} \mathrm{KC1}, 2.5 \mathrm{mM}$
Accepted for publication 23 April 1998 

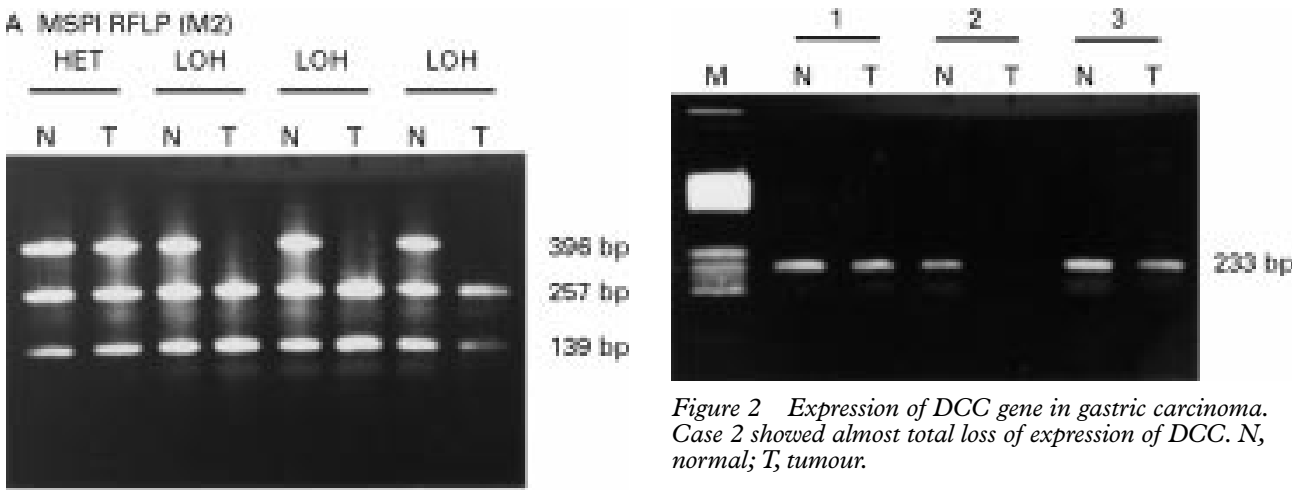

Figure 2 Expression of DCC gene in gastric carcinoma. Case 2 showed almost total loss of expression of DCC. $N$, normal; T, tumour.

DNA were performed for each set of PCR reactions.
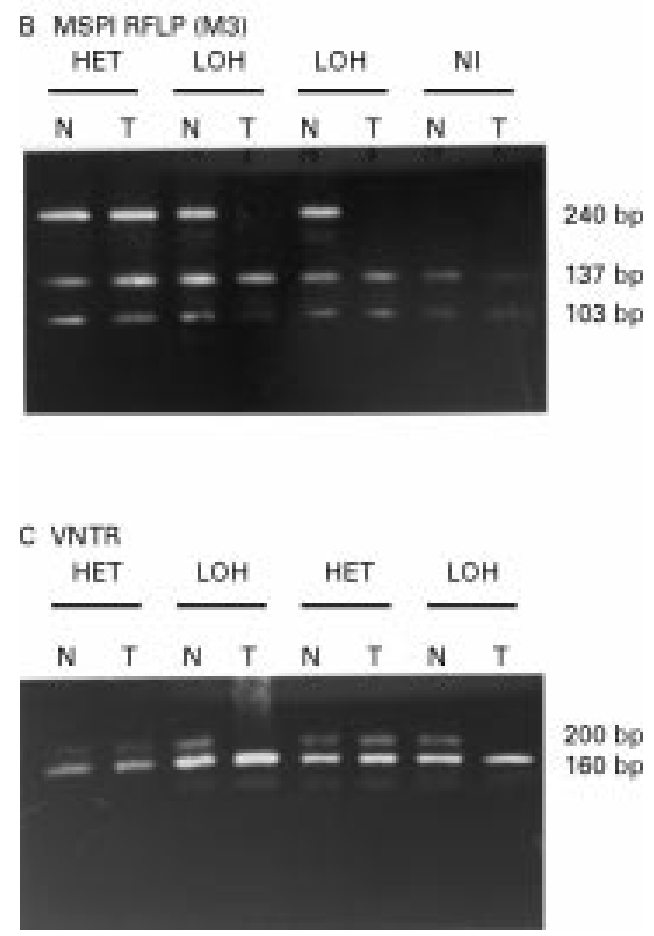

Figure 1 Loss of heterozygosity (LOH) assay of DCC gene in gastric carcinoma showing loss of heterozygosity in representative cases at M2 (A), M3 (B), and VNTR $(C)$. HET, retained heterozygosity; N, normal DNA; NI, not informative; T, tumour DNA.

$\mathrm{MgC1}_{2}, 0.1 \mu \mathrm{g} / \mu \mathrm{l}$ bovine serum albumin, and 1 $\mu \mathrm{M}$ concentrations of sense and antisense primers. Then 2.5 units of Ampli Taq DNA polymerase were added and PCR was run at $94^{\circ} \mathrm{C}$ for 40 seconds, $56^{\circ} \mathrm{C}$ for 40 seconds, and $72^{\circ} \mathrm{C}$ for one minute for 35 cycles. For M2 and M3 polymorphism, ${ }^{21}$ PCR products were digested with MspI and analysed on $2.5 \%$ agarose gels. For VNTR polymorphism, ${ }^{22}{ }^{23}$ PCR products were directly separated on 2.5 gels. The gel was then stained with ethidium bromide and photographed under ultraviolet light. The primers were: 5'-TGCACCATGCTGAAGATTGT-3' (M2 sense); 5'-AGTACAACACAAGGTATGTG-3' (M2 antisense); 5'-CGACTCGATCCTACAAAAT-3' sense); 5'-TCTACCCAGGTCTCAGAG-3' (M3 antisense); 5'-GATGACATTTTCCCTCTAG-3' (VNTR sense); and 5'GTGGTTATTGCCTTGAAAAG-3' (VNTF antisense). Negative controls without genomic

DATA ANALYSIS

Photographs of ethidium stained gels were read by two independent observers. Loss of heterozygosity and loss of expression were defined by a visible change in that allele to allele ratio in tumour compared with matching normal tissue. A reduction of allelic intensity in tumour of more than $50 \%$ compared with matching tissue was taken to indicate loss of heterozygosity or loss of expression.

Associations between variables were tested with the $\chi^{2}$ test. A probability (p) value of less than 0.05 was considered to be statistically significant.

\section{Results}

Loss of heterozygosity of the DCC gene was determined by PCR in 51 specimens of gastric cancer. To increase assay sensitivity, three different sites-M2, M3, and VNTR-were used in the study. Loss of heterozygosity of DCC was observed in nine of $47(19.0 \%)$ at M2, seven of $50(14 \%)$ at M3, and three of 26 $(11.5 \%)$ at VNTR sites of informative cases, respectively (fig 1 ). If a positive allelic deletion of DCC was judged by loss of heterozygosity at one or any combination of these three sites, the incidence of loss of heterozygosity at the DCC locus was $35.3 \%$ (18/51). Loss of heterozygosity was detected in $38.5 \%(10 / 26)$ of intestinal type of gastric cancer and $34.8 \%$ (8/23) of diffuse type of gastric cancer. Loss of expression of the DCC gene was observed in $49 \%$ of cases (25/51) (fig 2). The incidence of loss of expression was $61.5 \%(16 / 26)$ in intestinal type and $39.1 \%(9 / 23)$ in diffuse type. A $\chi^{2}$ test showed that there was no significant difference in the distribution of loss of heterozygosity and loss of expression between the two types of gastric cancer ( $p>0.05)$.

Correlations between loss of heterozygosity and loss of expression of DCC and clinicopathological data of gastric cancer are illustrated in table 1. A $\chi^{2}$ test showed that loss of heterozygosity of DCC was significantly greater in the gastric cancer of stage III-IV than that in stage I-II $(p<0.05)$. The association of loss of heterozygosity and loss of expression was such that most cases of loss of heterozygosity (17/18) were accompanied by loss of expression, although the frequency of loss of expression was greater than of loss of heterozygosity. 
Table 1 Relation of loss of heterozygosity ( $L O H$ ) and loss of expression (LOE) of DCC with clinicopathological variables

\begin{tabular}{llll}
\hline Clinicopathological variable & No & LOH (\%) & LOE (\%) \\
\hline Grade (differentiation) & & $9(37.5)$ & $13(54.2)$ \\
$\begin{array}{l}\text { Well/moderately differentiated } \\
\text { Poorly differentiated }\end{array}$ & 24 & $7(43.8)$ & $8(50.0)$ \\
Mucinous carcinoma & 16 & $2(18.2)$ & $4(36.4)$ \\
Tumour size & 11 & $5(25.0)$ & $11(55.0)$ \\
$\leqslant 5 \mathrm{~cm}$ & & $13(41.9)$ & $14(45.2)$ \\
$<5 \mathrm{~cm}$ & 20 & & $6(27.8)$ \\
Serosal invasion & 31 & $13(39.4)$ & $19(57.5)$ \\
Absent & 18 & $6(25.0)$ & $9(37.5)$ \\
Present & 33 & $12(44.4)$ & $16(59.2)$ \\
Lymph node metastasis & & & $7(33.3)$ \\
Absent & 24 & $3(14.3)$ & $18(60.0)$ \\
Present & 27 & $15(50.0)^{\star}$ & \\
Clinical staging & & & \\
Stages I-II & 21 & & \\
Stages III-IV & 30 & &
\end{tabular}

\section{Discussion}

The DCC gene is located on human chromosome 18q21.3. Inactivation of this gene is closely related to the pathogenesis of colorectal, oesophageal, and pancreatic carcinoma. DCC is regarded as a susceptibility gene in the stepwise evolution of gastrointestinal neoplasms. Uchino et al and Ranzani et al reported rates of loss of heterozygosity of DCC in gastric cancer of $61 \%$ and $42.9 \%$ respectively. ${ }^{1623}$ The rate was $35.3 \%$ in our study. These findings suggest that involvement of the DCC gene in the pathogenesis of gastric cancer occurs through loss of heterozygosity.

Although there are many reports on loss of heterozygosity of chromosome $18 \mathrm{q}$, there are few reports on DCC mRNA levels in clinical cases. ${ }^{24}$ The RT-PCR method has been used to detect DCC mRNA in most investigations because the amount is too small to be detected by northern hybridisation. In this study we have confirmed that there is loss of expression of DCC mRNA in gastric cancers using RT-PCR. This suggests that the inactivation of DCC plays an important role in the pathogenesis of gastric cancer.

The histological progression associated with intestinal type gastric cancer has been well documented, with apparent evolution through a sequence of chronic active gastritis, intestinal metaplasia, and dysplasia. ${ }^{25}{ }^{26}$ Lesions indicating an adenoma-carcinoma sequence similar to that in the colorectum is also observed in the stomach. ${ }^{27}$ In the present study we found that the frequency of loss of expression of DCC was $61.5 \%$ in the intestinal type of gastric cancer but only $39.1 \%$ in diffuse cancers. Although the rate of loss of expression showed no statistical difference between the two types of gastric cancer, similarities in genetic alterations between colorectal carcinoma and the intestinal type of carcinoma may reflect a common pathogenic pathway. On the other hand, the rate of loss of heterozygosity at the DCC locus was similar between the two types of gastric cancer. Whether the mechanisms underlying loss of heterozygosity and loss of expression of the DCC gene are different in the two types of gastric cancer needs further investigation.
The DCC gene encodes a molecule which shares high homology with the neural cell adhesion molecule. ${ }^{20}$ Cell adhesion molecules are cell surface receptors which play critical roles during processes such as embryogenesis, thrombosis, wound healing, cell homing, immunoreaction, and tumour progression and metastasis. The inactivation of the DCC gene may result in malignant transformation of the cells and invasion and metastasis by a tumour. Kato et al found that the incidence of loss of heterozygosity at the DCC locus in colorectal carcinoma was significantly greater for patients with liver metastases than those without. ${ }^{28}$ KikuchiYanoshita et al and Iino et al observed that the expression of DCC mRNA was greatly reduced or not detectable in invasive colorectal carcinoma in comparison with malignant adenoma and intramucosal carcinoma. ${ }^{17}{ }^{29}$ They showed that the inactivation of the DCC gene was associated with the progression of early stage carcinoma to advanced stage. ${ }^{29}$ Itoh et al found that the expression level of DCC mRNA was lower in liver metastasis than in primary carcinoma. ${ }^{30}$ These findings imply that the inactivation of the DCC gene occurs at a late stage in the evolution of colorectal carcinoma and may be of prognostic significance. Similar conclusions were expressed in studies of oesophageal and pancreatic carcinomas. ${ }^{831}$

In our study the rate of loss of heterozygosity of DCC increased in parallel with increase in tumour size, depth of invasion, and metastasis to lymph nodes, and loss of expression of DCC often occurred in gastric cancer of stages III-IV with lymph node metastasis. Although these findings did not show statistical significance, they suggest that DCC may play a role in the proliferation, invasion, and metastasis of gastric cancer. The frequency of loss of heterozygosity was significantly higher in stage III-IV than that in stage I-II, indicating a relation to advancing malignancy. Ranzani et al described similar findings. ${ }^{23}$ Thus it is possible that loss of heterozygosity and loss of expression of DCC may serve as prognostic factors for gastric cancer. However, more cases need to be examined to show the correlations between loss of heterozygosity and loss of expression with other variables and their independent prognostic significance.

In a preliminary study of the relation between loss of heterozygosity and loss of expression we have shown, as have others, ${ }^{32}$ that loss of heterozygosity does not seem to be necessary for loss of expression of DCC mRNA. Presumably there are several explanations for loss of expression such as alterations in sequences controlling transcriptional regulation, point mutation or insertions within the DCC gene, or alterations in other genes controlling DCC gene expression. Further studies are required to examine these alternative mechanisms.

The DCC gene was originally identified as a candidate tumour suppressor gene in colon carcinogenesis on the basis of allelic losses in chromosome $18 \mathrm{q} 21$ in more than $60 \%$ of colon cancers. ${ }^{162033}$ The possibility that $18 \mathrm{q}$ carries a colonic tumour suppressor gene is supported by 
chromosomal transfer experiments showing that one normal copy of chromosome 18 is sufficient to suppress the tumorigenicity of human colon carcinoma cell lines. ${ }^{34}{ }^{35}$ However, the accumulated evidence has failed to implicate DCC conclusively as the colorectal tumour suppressor gene on chromosome 18q. Recent in vitro studies in rodents have provided evidence that DCC might function as a receptor for the axonal chemoattractant netrin-1. Inactivation of the murine DCC gene caused defects in axonal projection that are similar to those observed in netrin-1 deficient mice but did not affect growth, differentiation, morphogenesis, or tumorigenesis in mouse intestine. ${ }^{36}{ }^{37}$ In addition, a study of the pattern of DCC mRNA and protein expression in surgically resected colonic cancer tissues has found that DCC protein was detected consistently in colorectal carcinoma and colon liver metastases by western blot analysis, and was not completely lost in any of the tumour specimens examined, even within metastatic cancers. ${ }^{38}$ These data may suggest that the DCC gene is not the main tumour suppressor gene in the region of chromosome $18 \mathrm{q} 21$. Other tumour suppressor genes present in the region of homozygous deletion at chromosome $18 \mathrm{q} 21$ may contribute to the development of colorectal carcinoma, such as the candidate tumour suppressor DPC4 gene in pancreatic cancer. ${ }^{39}$ In our opinion this is unlikely, since there is functional evidence supporting the role of DCC as a tumour suppressor. ${ }^{40}$ Moreover, recent studies have shown that the frequency of alterations of DPC4 was relatively low, at $16.7 \%$ (five of 31 colorectal cancers) compared with $60 \%$ cases reported to have allelic loss at $18 \mathrm{q} 21 .{ }^{41}$

Our data suggest that loss of heterozygosity and loss of expression of DCC appear to play an important role in the progression of gastric cancer, supporting the view that DCC functions as suppressor gene. However, additional functional studies in model systems using the full length DCC cDNA will be required to understand the role of DCC in tumour progression.

This project was supported by the National Funds of Natural Science of China, No 39470332 .

1 Weinberg RA. Tumor suppressor genes. Science 1991;254:1138-46.

2 Malkin D, Friend F. The role of tumor suppressor genes in familial cancer. Semin Cancer Biol 1992;3:121-30.

3 Levine LA, Momand J, Finlay CA. The p53 tumor suppressor gene. Nature 1991;351:453-6.

4 Vogelstein B, Fearon ER, Hamilton SR, et al. Genetic alterations during colorectal tumor development. $N \mathrm{Engl} \mathcal{F}$ Med 1988;319:525-32.

5 Cho KR, Oliner JD, Simons JW, et al. The DCC gene: structural analysis and mutations in colorectal carcinomas. Genomics 1994;19:525-31.

6 Cropp CS, Lidereau R, Campbell G, et al. Loss of heterozygosity on chromosome 17 and 18 in breast carcinoma: two additional regions identified. Proc Natl Acad Sci USA 1990 87:7737-41

7 Devilee P, van Vliet M, Kuipers-Dijkshoorn N, et al. Somatic genetic changes on chromosome 18 in breast carcinomas: is the DCC gene involved? Oncogene 1991;6:311-15.

8 Hohne MW, Halatsch ME, Kahl GF, et al. Frequent loss of expression of the potential tumor suppressor gene DCC in ductal pancreatic adenocarcinoma. Cancer Res 1992;52: $2616-19$

9 Gao X, Honn KV, Grignon D, et al. Frequent loss of expression and loss of heterozygosity of putative tumor suppressor gene DCC in prostatic carcinomas. Cancer Res 1993;53:2723-7.

10 Peng HQ, Bailey D, Bronson D, et al. Loss of heterozygosity of tumor suppressor genes in testis cancer. Cancer Res 1995;55:2871-5.
11 Reyes-Mugica M, Rieger-Christ K, Ohgaki H, et al. Loss of DCC expression and glioma progression. Cancer Res 1995; 57:382-6.

12 Scheck AC, Coons SW. Expression of the tumor suppressor gene DCC in human gliomas. Cancer Res 1993;53:5605-9.

13 Reale MA, Reyes-Mugica M, Pierceall WE, et al. Loss of DCC expression in neuroblastoma is associated with disease dissemination. Clin Cancer Res 1996;2:1197-202.

14 Porfiri E, Secher-Walker LM, Hoffbrand AV, et al. DCC tumor suppressor gene is inactivated in hematologic malig-
nancies showing monosomy 18. Blood 1993;81:2696-701.

15 Miyake K, Inokuchi K, Dan K, et al. Alteration in the deleted-in-colorectal-carcinoma gene in human primary leukemia. Blood 1993;82:927-30.

16 Uchino S, Tsuda H, Noguchi M, et al. Frequent loss of hetrozygosity at the DCC locus in gastric cancer. Cancer Res 1992;52:3099-102.

17 Kikuchi-Yanoshita R, Konishi M, Fukunari H, et al. Loss of expression of the DCC gene during progression of colorectal carcinomas in familial adenomatous polyposis and nonfamilial adenomatous polyposis patients. Cancer Res 1992; 52:3801-3.

18 Simon B, Weinel R, Hohne M, et al. Frequent alterations of the tumor suppressor genes p53 and DCC in human pancreatic carcinoma. Gastroenterology 1994;106:1645-51.

19 Shibata D, Reale MA, Lavin P, et al. Loss of DCC expression and prognosis in colorectal cancer. $N$ Engl $\mathcal{F}$ Med 1996;335:1727-32.

20 Fearon ER, Cho KR, Kern SE, et al. Identification of a chromosome $18 \mathrm{q}$ gene that is altered in colorectal chromosome 18q gene that is

21 Parry PJ, Markie D, Fearon ER, et al. PCR-based detection of two MspI polymorphic sites at D18S8. Nucleic Acids Res 1991;19:6983.

22 Huang Y, Boynton RF, Blount PL, et al. Loss of heterozygosity involves multiple tumor suppressor genes in human esophageal cancers. Cancer Res 1992;52:6525-30.

23 Ranzani GN, Renault B, Pellegata NS, et al. Loss of heterozygosity and K-ras gene mutation in gastric cancer. Hum Genet 1993;92:244-9.

24 Kataoka M, Okabayashi T, Orita K. Decreased expression of DCC mRNA in gastric and colorectal cancer. Fpn f Surg 1995;25:1001-7.

25 Jass JR. Role of intestinal metaplasia in the histogenesis of gastric carcinoma. $\mathcal{F}$ Clin Pathol 1980;33:801-10.

26 Correa P, Shiao Y. Phenotypic and genotypic events in gastric carcinogenesis. Cancer Res 1994;54(S):1941-3.

27 Tatsuta $M$, Iishi $\mathrm{H}$, Baba $\mathrm{M}$, et al. Expression of c-myc mRNA as an aid in histologic differentiation of adenoma from well differentiated adenocarcinoma in the stomach. Cancer 1994;73:1795-9.

28 Kato M, Ito Y, Kobayashi S. Detection of DCC and Ki-ras gene alterations in colorectal carcinoma tissue as prognostic markers for liver metastatic recurrence. Cancer 1996;77: 1729-35.

29 Iino H, Fukayama M, Maeda Y, et al. Molecular genetic for clinical management of colorectal carcinoma. Cancer 1994; 73:1324-31.

30 Itoh F, Hinoda Y, Ohe M, et al. Decreased expression of DCC mRNA in human colorectal cancers. Int $f$ Cancer 1993;53:260-3.

31 Miyake S, Nagai K, Yoshino K, et al. Point mutations and allelic deletion of tumor suppressor gene DCC in human esophageal squamous cell carcinomas and their relation to metastasis. Cancer Res 1994;54:3007-10.

32 Enomoto T, Fujita M, Cheng C, et al. Loss of expression and loss of heterozygosity in the DCC gene in neoplasms of the human female reproductive tract. Br F Cancer 1995;71: 462-7.

33 Boland CR, Sato J, Appelman HD, et al. Microallelotyping defines the sequence and tempo of allelic losses at tumor suppressor gene loci during colorectal cancer progression. Nature Med 1995;1:902-9.

34 Tanaka K, Oshimura M, Kikuchi R, et al. Suppression of tumorigenicity in human colon carcinoma cells by introduction of normal chromosome 5 or 18. Nature 1991; 349:340-2.

35 Goyette MC, Cho K, Fasching CL, et al. Progression of colorectal cancer is associated with multiple tumor suppressor gene defects but inhibition of tumorigenicity is accomplished by correction of any single defect via chromosome transfer. Mol Cell Biol 1992;12:1387-95.

36 Kolodziej PA, Timpe LC, Mitchell KJ, et al. Frazzled encodes a Drosophia member of the DCC immunoglobuin subfamily and is required for CNS and motor axon guidance. Cell 1996;87:197-204.

37 Fazeli A, Dickinson SL, Hermiston ML, et al. Phenotype of mice lacking functional deleted in colorectal cancer CDCC gene. Nature 1997;386:796-804.

38 Gotley DC, Reeder JA, Fawcett J, et al. The deleted in colon cancer (DCC) gene is consistently expressed in colorectal cancers and metastases. Oncogene 1996;13:787-95.

39 Hahn SA, Schutte M, Hoque ATMS, et al. DPC4, a candidate tumor suppressor gene at human chromosome 18q21.1. Science 1996;271:350-3.

40 Klingelhutz AJ, Hedrick L, Cho KR, et al. The DCC gene suppresses the malignant phenotype of transformed human epithelial cells. Oncogene 1995;10:1581-6.

41 Takagi Y, Kohmura H, Futamura M, et al. Somatic alterations of the DPC4 gene in human colorectal cancers in vivo. Gastroenterology 1996;111:1369-72. 